\title{
Editorial
}

\section{Modulating susceptibility and severity of COVID-19: Role of immuno-nutrition}

\author{
Shefali Mehta ${ }^{1, *}$, Aditi Mehta ${ }^{2}$, Vishwa Mehta ${ }^{3}$ \\ ${ }^{1}$ Ravindra Nath Tagore Medical College, Udaipur, Rajasthan, India \\ ${ }^{2}$ Hinduja Hospital, Mumbai, Maharashtra, India \\ ${ }^{3}$ Geetanjali Medical College \& Hospital (GMCH), Udaipur, Rajasthan, India
}

\section{A R T I C L E I N F O}

Article history:

Received 01-12-2020

Accepted 15-12-2020

Available online 29-12-2020
(C) This is an open access article distributed under the terms of the Creative Commons Attribution License (https://creativecommons.org/licenses/by/4.0/) which permits unrestricted use, distribution, and reproduction in any medium, provided the original author and source are credited.

\section{Introduction}

On December 12, 2019 a new coronavirus (SARS-CoV2) emerged in Wuhan, China, triggering a pandemic of severe acute respiratory syndrome in humans (COVID19). ${ }^{1}$ Although, the pandemic has affected all the groups, severe pathology and mortality is disproportionately highest in the elderly, underrepresented minorities (blacks/African Americans and Latinos), and/or in those with underlying comorbidities. $^{2}$ Thus, the scientific community across the world is putting uni-directional efforts to develop therapy and prevention strategies from the available resources to defeat COVID-19. In this regards, these communities have unanimous view that immune-nutrition can play a pivotal role in improving immune responses against viral infections.

Initially, when the pandemic hit the world, it was difficult to identify the risk factors and etiology of COVID-19, further, making it difficult for the scientists for disease prevention. With the passage of time, it has been found that obesity represents a significant risk factor both for COVID-19 susceptibility and prognosis. ${ }^{3}$ Around $13 \%$ of the world population is obese, therefore, immune-nutrition can be an effective prophylactic measure to lower the burden of COVID-19 disease. ${ }^{4}$

\footnotetext{
* Corresponding author.

E-mail address: shefalimehta202@gmail.com (S. Mehta).
}

Inflammation plays a fundamental role in the pathogenesis and progression of COVID-19, ranging from common colds to fatal cases of pneumonia due to the cytokine release syndrome (CRS) that affected patients, determining the severe conditions. ${ }^{5}$ Infectious diseases, like COVID-19, are characterized by an increased production of adiponectin. ${ }^{6}$ It seems interesting the possibility to improve the action of adiponectin through diet intervention. ${ }^{7}$ An optimal nutritional status guarantees the main modulating processes of inflammatory and oxidative stress, both connected to the immune system. A balanced diet, rich in some foods, is associated with anti-inflammatory and immunomodulatory compounds, including vitamins $(\mathrm{C}, \mathrm{D}$, and $\mathrm{E}$ ) and minerals (zinc and selenium), and may influence human nutritional status. ${ }^{8}$

Prebiotic from fruits and vegetables is well-established to modulate the gut microbiota and numerous benefits have been reported in chronic inflammatory and metabolic conditions. ${ }^{9}$ Moreover, increased dietary fiber consumption is linked to reduced mortality rates in respiratory-related diseases and improved lung function. Thus, plant-based diets, functional foods, and supplements present a promising strategy for protecting against respiratory infections. ${ }^{10}$

Therefore, it can be concluded that personalized immune-nutrition for obese patients should be the first therapeutic choice to reduce the risk of infections and the disease course in COVID-19 patient. Immuno-nutrition 
can decrease the risk of infections, reducing characteristic inflammation state. In addition, immune-nutrition would be fundamental to support the immune response and protein synthesis in severe phase of COVID-19.

\section{Conflicts of interest}

None.

\section{References}

1. Wang C, Horby PW, Hayden FG, Gao GF. A novel coronavirus outbreak of global health concern. Lancet. 2020;395(10223):470-3. do1:10.1016/s0140-6736(20)30185-9.

2. Dietz W, Santos-Burgoa C. Obesity and its Implications for COVID19 Mortality. Obes. 2020;28(6):1005. 001:10.1002/oby.22818.

3. Muscogiuri G, Pugliese G, Barrea L, Savastano S, Colao A. The "Achilles heel" for COVID-19? Metabolism. Philadelphia: W. B. Saunders; 2020.

4. Obesity and overweight. 2020;Available from: https://www.who.int/ news-room/fact-sheets/detail/obesity-and-overweight.

5. Olszak T, Neves JF, Dowds CM, Baker K, Glickman J, Davidson NO, et al. Protective mucosal immunity mediated by epithelial CD1d and IL-10. Nat. 2014;509:497-502.

6. McLaughlin T, Ackerman SE, Shen L, Engleman E. Role of innate and adaptive immunity in obesity-associated metabolic disease. $J$ Clin Investig. 2017;127(1):5-13. doi:10.1172/jci88876.
7. Reis $\mathrm{C}$, Bressan $\mathrm{J}$, Alfenas R. Effect of the diet components on adiponectin levels. Nutr Hosp. 2010;25:881-889.

8. EFSA. Guidance on the scientific requirements for health claims related to the immune system, the gastrointestinal tract and defence against pathogenic microorganisms. EFSA J. 2016;14:4369.

9. Holscher HD. Dietary fiber and prebiotics and the gastrointestinal microbiota. Gut Microbes. 2017;8(2):172-84.

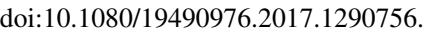

10. Shinde T, Hansbro PM, Sohal SS, Dingle P, Eri R, Stanley $\mathrm{R}$, et al. Microbiota Modulating Nutritional Approaches to Countering the Effects of Viral Respiratory Infections Including SARS-CoV-2 through Promoting Metabolic and Immune Fitness with Probiotics and Plant Bioactives. Microorganisms. 2020;8(6):921. do1:10.3390/microorganisms8060921.

\section{Author biography}

Shefali Mehta, Assistant Professor

Aditi Mehta, Clinical Assistant

Vishwa Mehta, MBBS 2nd Year Student

Cite this article: Mehta S, Mehta A, Mehta V. Modulating susceptibility and severity of COVID-19: Role of immuno-nutrition. Panacea J Med Sci 2020;10(3):176-177. 